\title{
A systematic study of element mobilisation from gas shales during hydraulic fracturing
}

\author{
I. OTALEGA ${ }^{1,2 *}$, S.C. APTE ${ }^{2}$, J. KING' ${ }^{2}$, K. J. DOBSON ${ }^{1}$, \\ Z. K. SHIPTON ${ }^{1}$ AND J. C. RENSHAW ${ }^{1}$ \\ ${ }^{1}$ Department of Civil and Environmental Engineering, \\ University of Strathclyde, Glasgow G1 1XJ, UK \\ (*correspondence: izabella.otalega@strath.ac.uk) \\ ${ }^{2}$ CSIRO Land and Water, Lucas Heights, NSW 2234,
}

Australia

The large quantities of wastewater produced throughout the lifetime of a shale gas well can contain heavy metals and other regulated potentially toxic elements. These can be mobilised from the target formation by some of the additives present in the hydraulic fracturing fluids (HFF). High levels of inorganic geogenic chemicals may pose a hazard to the environment through accidental releases such as spills of untreated wastewater. The concentration of mobilised elements and the hazard they pose is uncertain and is likely dependant on the chemical agents used in HFF, groundwater composition and the trace element content of targeted shale gas formation.

Laboratory protocols were developed to investigate the release of inorganic contaminants of potential concern (e.g. $\mathrm{As}, \mathrm{Co}, \mathrm{Cu}, \mathrm{Pb}, \mathrm{Se}$ ) from shale gas formations around the world. Powdered rock samples were leached for up to 360 hours at elevated temperature $\left(80^{\circ} \mathrm{C}\right)$ and a range of pressures (1-200 bar), with synthetic HFF and synthetic groundwater (SGW). Elemental concentrations released into solution were generally much higher in the HFF leachates than in the SGW treatments, indicating that the chemical additives in the HFF influenced element mobilisation.

SEM and EDX images show substantial mineral etching and precipitation of secondary phases on shale chips leached for 360 hours with $\mathrm{HFF}$ at $80^{\circ} \mathrm{C}$ and $\sim 180$ bar when compared to the SGW experiment. Time-series data also show evidence of mineral dissolution and subsequent precipitation of new phases, which resulted in sequestration of a number of trace elements that were initially mobilised into the solution. We also observed that the carbonate content of the unreacted shale sample had a strong control on the final $\mathrm{pH}$ of the HFF leachates.

This study shows that additives can enhance the release of geogenic chemicals, but also that subsequent precipitation within the fracture system could limit ultimate release to surface. 